\title{
Strengthening primary healthcare in India
}

\author{
UK-India partnership offers promise if it connects with existing efforts and stakeholders
}

\author{
Lalit Dandona distinguished research professor ${ }^{1}$, Jagdish Prasad director general of health services ${ }^{2}$
}

${ }^{1}$ Public Health Foundation of India, New Delhi 110070, India; ${ }^{2}$ Ministry of Health and Family Welfare, Government of India, New Delhi, India

The concept of primary healthcare was brought to the world's attention in a consolidated manner by the Declaration of Alma-Ata in 1978. ${ }^{1}$ This asserted that the overall wellbeing of all people could be achieved through a comprehensive primary healthcare approach that takes into account the broader socioeconomic determinants of health and is driven by governments using practical, scientifically sound, and socially acceptable methods. In the following years this approach was criticised by some for being too broad, but the notion of achieving health for all with primary healthcare at the centre has recently been revived. ${ }^{2}$ The "white paper" on an India-UK partnership on primary healthcare (doi:10.1136/bmj. e3151) - published online this week in the $B M J$ and prepared as guidance to the India-UK CEO Forum set up by the prime ministers of the two countries-builds on this approach. ${ }^{3}$

In 1946, in the run up to India's independence, the Bhore Committee recommended a health system for India that was largely consistent with the principles of comprehensive primary healthcare, emphasising prevention, basic healthcare for all, linkages between the different levels of care, and the broader determinants of health. ${ }^{4}$ These recommendations were poorly implemented over the subsequent decades for reasons that included relatively poor allocation of public funding for health, inadequate linkages between different social sectors, and incomplete development of the infrastructure needed for comprehensive primary healthcare. Efforts to bring primary healthcare to the forefront have, however, continued, and these include the People's Health Movement, ${ }^{5}$ the launch of the National Rural Health Mission in 2005, ${ }^{6}$ the Lancet India series on universal health coverage in $2011,{ }^{7}$ and a report on universal health coverage for India in 2011 by a high level expert group instituted by the Planning Commission of India. ${ }^{8}$ It is essential that primary healthcare in India is strengthened because many basic health indicators continue to be poor-for example, infant mortality in India was 47 per 1000 live births in 2010, with a range of 10 per 1000 in Goa to 62 per 1000 in Madhya Pradesh. ${ }^{9}$

Collaborations and partnerships are essential for large scale improvements in any aspect of society, and the white paper on partnership between India and the United Kingdom on primary healthcare offers such an opportunity. ${ }^{3}$ It outlines a strategic analysis and then a set of partnership opportunities, which include collaborative training in primary care across health disciplines; enhancing the status of primary healthcare in India using the experience of the UK's General Medical Council and Royal College of General Practitioners; developing affordable medical technologies that draw on the respective strengths of India and the UK; developing public-private partnerships using the experience of the UK National Health Service; helping develop quality standards and governance arrangements for primary care with inputs from the UK National Institute for Health and Clinical Excellence and the Department for International Development; and collaborative research and development of primary healthcare models and technologies. It ends by suggesting specific actions for the India-UK Forum, including the development of primary healthcare with UK support in a small number of Indian states, which could then be used to guide scale up across other states, and joint exploration by the India-UK governments of commercial opportunities that could arise from the partnership.

The white paper offers an interesting and useful list of partnership opportunities between the two countries to strengthen primary healthcare in India. While implementing these it would be wise to keep the following issues in mind. Firstly, the proposed activities need to be positioned to complement the efforts already going on in India to strengthen primary healthcare, such as the current discussion on implementing the Report on Universal Health Coverage commissioned by the Planning Commission of India and further development of the National Rural Health Mission into a National Health Mission. ${ }^{6}$ Synergy with these larger efforts would probably improve efficiency of the activities proposed by the India-UK partnership.

Secondly, a holistic framework is needed to track how these activities might help the development of primary healthcare in India and assess this effort's impact over time. To ensure sound conceptualisation, monitoring, and assessment of the benefits of these activities to society, the proposed activities need to be placed in an overall framework. ${ }^{10}$

Thirdly, existing India-UK collaborative efforts in capacity building may have useful lessons-for example, two strategic awards by the Wellcome Trust to the Public Health Foundation 
of India and a consortium of 15 UK universities and institutions have been supporting collaborative capacity building in research and education in public health in India over the past three years. $^{11} 12$

Fourthly, wider discussion among the relevant stakeholders in India to refine and implement the proposed activities would be beneficial. For example, it would be important to engage private providers and those who practise the Indian system of medicine because they are the first point of contact for healthcare for a large proportion of Indians, and engaging Indian academic and policy institutions would increase the likelihood of sustaining the proposed activities.

Fifthly, the white paper generally does not cover the broader determinants of health beyond the traditional health sector. Although it is fine to have a defined scope, it is important to remember that this is not the full scope of comprehensive primary healthcare and expectations should be adjusted accordingly.

Sixthly, the white paper suggests exploration of the commercial opportunities arising from this partnership. Although this could be mutually beneficial to India and the UK, this aspect must be handled wisely so that commercial interests do not outweigh the partnership's goal of working for the public good.

Finally, the partnership proposed in the white paper has to be one of equals. This should include equality between the Indian and UK partners in conceptualisation, development of processes, implementation, and evaluation. The Indian and UK parties will have different, probably complementary, skills to offer to the partnership, which if harnessed with mutual respect would have the best chance of successful outcomes.
Competing interests: All authors have completed the ICMJE uniform disclosure form at www.icmje.org/coi_disclosure.pdf (available on request from the corresponding author) and declare: no support from any organisation for the submitted work; no financial relationships with any organisations that might have an interest in the submitted work in the previous three years; no other relationships or activities that could appear to have influenced the submitted work.

Provenance and peer review: Commissioned; not externally peer reviewed.

LD is also professor of global health at the Institute for Health Metrics and Evaluation, University of Washington, Seattle, WA, USA.

1 Declaration of Alma-Ata. 1978. www.who.int/hpr/NPH/docs/declaration_almaata.pdf.

2 WHO. The world health report 2008 - primary health care (now more than ever). 2008. www.who.int/whr/2008/en/index.html.

3 Rao M, Mant D. Strengthening primary healthcare in India: white paper on opportunities for partnership. BMJ 2012;344:e3151.

4 Report of the Health Survey and Development Committee (Bhore Committee). Delhi: Government of India, 1946. http://nihfw.org/NDC/DocumentationServices/Committe_and commission.html.

5 Jan Swasthya Abhiyan: People's Health Movement—India. http://phm-india.org/.

6 Ministry of Health and Family Welfare, Government of India. National Rural Health Mission http://mohfw.nic.in/NRHM.htm.

7 Reddy KS, Patel V, Jha P, Paul VK, Shiva Kumar AK, Dandona L; for the Lancet India Group for Universal Healthcare. Towards achievement of universal health care in India by 2020: a call to action. Lancet 2011;377:760-8.

8 High Level Expert Group Report on Universal Health Coverage for India. Submitted to the Planning Commission of India. 2011. www.phfi.org/images/what_we_do/HLEG Report_complete_file_final.pdf.

9 Registrar General, India. SRS Bulletin Vol 46, No 1. December 2011. http://pib.nic.in/ archieve/others/2012/feb/d2012020102.pdf.

10 Dandona L. Conceptualizing health policy. Natl Med J India 2002;15:226-31.

11 PHFI-UK Consortium Capacity Building Programme. http://wtp-india-ukc.org/.

12 South Asia Network for Chronic Disease. www.sancd.org/.

Cite this as: BMJ 2012;344:e3410

๑ BMJ Publishing Group Ltd 2012 